\title{
DIVERSIFIED ANALYSIS OF NUTRITIONAL STATUS IN COMMUNITY-DWELLING OLDER ADULTS IN JAPAN
}

\author{
M. Kawashima ${ }^{1}$, M. Kubota ${ }^{1,2}$, H. Saito ${ }^{1}$, S. Shinozuka
}

\begin{abstract}
Objectives: This study aimed to comprehensively analyze the nutritional status of community-dwelling older adults in Japan. Design and Participant: Participants included 48 outpatients (13 males and 35 females) aged $\geqq 65$ years who visited a private clinic in an urban city. Body height, body weight, and blood variables, including albumin, lymphocyte counts and total cholesterol, and pre-albumin, were obtained from the patient charts. The MNA-SF and nutritional intakes, using an established semiquantitative questionnaire, were conducted by an interview with a dietitian. Results: Nutritional risk assessment by MNA-SF revealed that 13 patients $(27.1 \%)$ were at a risk of malnutrition and 4 patients $(8.3 \%)$ demonstrated thinness, i.e., BMI $<18.5 \mathrm{~kg} / \mathrm{m}^{2}$. No statistical difference in terms of sex was found in the MNA-SF or BMI analyses. The caloric, protein, and lipid intake, adjusted by body weight, were significantly higher in females than in males. The daily caloric intake of 15 patients ( $31.3 \%$ ) was below the estimated energy requirements defined by Dietary Reference Intakes for Japanese (2015), and the frequency of low estimated energy requirements was significantly higher in males than in females. Multiple regression analysis demonstrated that both BMI and MNA-SF were associated with albumin levels. Conclusions: Our findings suggest that malnutrition is not prevalent among community-dwelling older adults in Japan. Albumin may work as indicators for predicting malnutrition. Considering the lower caloric, protein, and lipid intake of males compared with females, caregivers should note that older adult males may be at a higher risk of malnutrition.
\end{abstract}

Keywords: Malnutrition, older adults, MNA-SF, albumin, nutritional intake.

\section{Introduction}

The number of individuals aged $\geq 65$ years, hereafter referred to as older adults, has rapidly increased in developed countries. In Japan, according to the national census in 2015, approximately $27 \%$ of the entire population falls into this category (1). Under these circumstances, healthcare for older adults has become important in terms of minimizing both acute and chronic comorbidities and promoting healthy, active lifestyles. Nutritional care plays an integral role in health, regardless of the type of dwelling (i.e., community, nursing-care, or hospital) (2-4).

For adequate achievement of nutritional care, nutritional assessment is a necessary initial step. There are several methods for nutritional assessment, including short screening questionnaires, anthropometric measures, and laboratory markers. The Mini Nutritional Assessment (MNA) is a widely used screening tool for identifying individuals with malnutrition or those at a

1. Department of Human Life and Environment, Nara Women's University, Nara, Japan; 2. Faculty of Agriculture, Department of Food and Nutrition, Ryukoku University, Shiga, Japan; 3. Shinozuka Clinic, Osaka, Japan

Corresponding Author: Masaru Kubota, Faculty of Agriculture, Department of Food and Nutrition, Ryukoku University, Shiga, Japan, e-mail: masaru_kubota@chime. ocn.ne.jp

Received September 4, 2017

Accepted for publication September 11, 2017 risk of malnutrition (5). Because MNA contains specific questions related to older adults (i.e., independence, cognition, quality of life, and morbidity), the European Society for Clinical Nutrition and Metabolism recommends MNA as a commonly acceptable tool for nutritional screening in older adults (6). Recently, the MNA Short-Form (MNA-SF), which includes six questions from the original MNA, has been validated as a more suitable tool for older adults (7). Anthropometric measures, such as body weight, BMI, and calf circumferences, are also useful (8). Finally, among various laboratory markers, albumin level has been used as the gold standard for the diagnosis of malnutrition, although its accuracy and precision can be affected by inflammation or hepatic functions $(9,10)$. In order to compensate for this limitation, the Nutritional Control Status (CONUT) system, which utilizes several laboratory tests simultaneously, including albumin levels, total cholesterol levels and total lymphocyte counts has been developed for clinical use (11).

A nutritional intake study is a distinguished approach for the nutritional assessment, since it tries to focus on a causative factor of malnutrition. A careful investigation of nutrition, both quantitative (i.e., energy intake) and qualitative (i.e., nutrient quality), may provide means of preventing malnutrition (12); however, this method 
has limitations in the older adult population, given the higher rates of cognitive and functional decline, which may hamper the accuracy of dietary assessment (13). In addition, the standard of nutritional intakes, for example, estimated energy requirements (EER), may differ among countries, making it difficult to compare across populations of different countries. Therefore, it is essential to establish and utilize the standard values specific to each country (14).

As described above, each nutritional assessment methodology has its advantages and limitations. Therefore, our study utilized a mixed-methods approach (i.e., measurement of MNA-SF, BMI, laboratory markers, and nutritional intake measurements) to obtain a more comprehensive understanding of malnutrition prevalence and characteristics among community-dwelling older adults in Japan.

\section{Materials and methods}

\section{Study design and subjects}

This study was conducted between May and July 2014 on outpatients who visited Shinozuka Clinic, HigashiOsaka, a private clinic specializing in internal medicine. Higashi-Osaka is one of the satellite cities of Osaka, with a population of approximately 500,000, $27 \%$ of which are aged $\geq 65$ years. Among patients visiting the clinic during that period, 330 patients fulfilled the following inclusion criteria: (i) age $\geq 65$ years (definition of older adults in Japan), (ii) ambulant patients, and (iii) had data on body height and weight recorded within the last month. We asked these patients whether they were able to participate in the subsequent nutritional intake study, and 48 were finally enrolled in the study. The basic characteristics, such as sex, age, BMI, and underlying disease status, in these 48 patients were comparable with the 330 patients initially selected to participate (Table 1). This project was approved by the ethical and epidemiological committee of Nara Women's University.

\section{Measurement of body height, weight, MNA-SF and blood markers}

Body height and weight were measured by welltrained nurses. Height was measured to the nearest 0.1 $\mathrm{cm}$, and weight was measured to the nearest $0.1 \mathrm{~kg}$. BMI was calculated by dividing the body weight $(\mathrm{kg})$ by the square of height $(\mathrm{m})$. Nutritional risk assessment was performed using MNA-SF (7). Scores between 8 and 11 and $\leq 7$ were defined as malnutrition at risk and malnutrition, respectively. Data on serum albumin, total leukocytes counts with their differentials, total cholesterol, and pre-albumin levels were obtained from the recent patient charts within 1 month. C-reactive protein (CRP) levels at the time of sampling were $<1.0$ $\mathrm{mg} / \mathrm{dl}$ in all patients. The cutoff of albumin level $(<3.5$ $\mathrm{g} / \mathrm{dl})$, total cholesterol levels $(<180 \mathrm{mg} / \mathrm{dl})$ and total lymphocyte counts $(<1600 / \mu 1)$ were obtained from the CONUT study. CONUT scores were calculated as described by Ignacio de Ulibarri et al. (11), and the scores were classified as follows: healthy, $0-1$; light undernutrition, 2-4; moderate undernutrition, 5-8; and severe undernutrition, 9-12. For pre-albumin levels, we used a cutoff of $<21.0 \mathrm{mg} / \mathrm{dl}$, described by Takeda et al. (15).

Table 1

Basic characteristics of participants

\begin{tabular}{|c|c|c|c|c|}
\hline & & $\begin{array}{l}\text { Initial } \\
\text { participants }\end{array}$ & $\begin{array}{l}\text { Study } \\
\text { participants }\end{array}$ & p-value \\
\hline Total (n) & & 330 & 48 & \\
\hline \multirow[t]{2}{*}{ Sex } & Male & $125(37.9)^{*}$ & $13(27.1)$ & $0.147+$ \\
\hline & Female & $205(62.1)$ & 35 (72.9) & \\
\hline \multirow[t]{6}{*}{ Age (years) } & & 76 [65-95]§ & 74 [65-95] & $0.882 \ddagger$ \\
\hline & $65-69$ & $62(18.8)$ & $8(16.7)$ & $0.264 \dagger$ \\
\hline & $70-74$ & $90(27.3)$ & $17(35.4)$ & \\
\hline & $75-79$ & $73(22.1)$ & $10(20.8)$ & \\
\hline & $80-84$ & $64(19.4)$ & $4(8.3)$ & \\
\hline & $\geq 85$ & $41(12.4)$ & $9(18.8)$ & \\
\hline \multirow[t]{4}{*}{ BMI $\left(\mathrm{kg} / \mathrm{m}^{2}\right)$} & & $23.5[15.2-49.0]$ & 24.1 [16.5-40.6] & $0.542 \ddagger$ \\
\hline & $\leq 18.4$ & $23(7.0)$ & $4(8.3)$ & $0.536+$ \\
\hline & $18.5-24.9$ & $213(64.5)$ & $27(56.3)$ & \\
\hline & $\geq 25$ & $94(28.5)$ & $17(35.4)$ & \\
\hline \multicolumn{5}{|c|}{ Underlying disease } \\
\hline & Hypertension & 257 (77.9) & $43(89.6)$ & $0.061+$ \\
\hline & Diabetes Mellitus & $168(50.9)$ & $26(54.2)$ & $0.673+$ \\
\hline & Dyslipidemia & $227(68.8)$ & $34(70.8)$ & $0.775+$ \\
\hline & Liver Disease & $107(32.4)$ & $13(27.1)$ & $0.384 \dagger$ \\
\hline & Renal Disease & $22(6.7)$ & $3(6.3)$ & $0.972 \dagger$ \\
\hline & Hyperuricemia & $33(10.0)$ & $5(10.4)$ & $1.00+$ \\
\hline
\end{tabular}

* Numbers in parentheses indicate percentages. § Median and range in brakets are shown; +Chi-squared test or Fisher's exact test. ¥Mann-Whitney U test

\section{Nutritional intake study}

We collected nutritional information from each patient (i.e., nutritional intake in the last 1 week), using the established semiquantitative questionnaire "Excel Eiyoukun, FFG3.5" (Kenpaku-sha, Tokyo, Japan) (16). FFG3.5 consists of 29 food groups and estimates the amount of food group and nutrient ingested based on self-reported intake data (i.e., portion size and frequency). Portion size is a simple, countable unit used to describe the approximate amount of food in each dish. Our dietitian and chief investigator, $\mathrm{MK}$, conducted face-to-face interviews with the patients to obtain this information and demonstrated approximate portion sizes of different foods. 
Table 2

Comparison of various nutritional parameters

\begin{tabular}{|c|c|c|c|c|}
\hline & All & Male & Female & $\mathrm{p}$ value \\
\hline Age & $74[65-95]^{*}$ & 74 [65-95] & 74 [65-95] & $0.614+$ \\
\hline Number of patients $\left(<18.5 \mathrm{~kg} / \mathrm{m}^{2}\right)$ & $4(8.3) \S$ & $1(7.7)$ & $3(8.6)$ & $1.00 \ddagger$ \\
\hline MNA-SF & $12.5[9-14]$ & $13[10-14]$ & $12[9-14]$ & $0.214+$ \\
\hline Albumin (g/dl) & $4.35[3.1-4.7]$ & $4.1[3.3-4.7]$ & $4.4[3.1-4.7]$ & $0.016+$ \\
\hline Number of patients $(<3.5 \mathrm{~g} / \mathrm{dl})$ & $3(6.3)$ & $2(15.4)$ & $1(2.9)$ & $0.174 \ddagger$ \\
\hline Total cholesterol (mg/dl) & 189 [126-259] & $176[142-207]$ & 195 [126-259] & $0.059+$ \\
\hline Number of patients $(<180 \mathrm{mg} / \mathrm{dl})$ & $21(43.8)$ & $7(53.8)$ & $14(40.0)$ & $0.516 \neq$ \\
\hline Number of patients $(<21.0 \mathrm{mg} / \mathrm{dl})$ & $5(11.1)$ & $2(15.4)$ & $3(8.6)$ & $0.593 \neq$ \\
\hline CONUT score & & & & $0.279 \neq$ \\
\hline $0 \sim 1$ & $40(83.3)$ & $9(69.2)$ & $31(88.6)$ & \\
\hline $2 \sim 4$ & $7(14.6)$ & $4(30.8)$ & $3(8.6)$ & \\
\hline $5 \sim 8$ & $1(2.1)$ & 0 & $1(2.8)$ & \\
\hline $9 \sim 12$ & 0 & 0 & 0 & \\
\hline
\end{tabular}

U test $\neq$ Chi-squared test or Fisher's exact test

\section{Statistical analysis}

Differences in categorical variables were examined using the Chi-squared test or Fisher's exact test and differences in continuous variables were examined using the Mann-Whitney U test. Correlation between albumin and pre-albumin levels was estimated using the Spearman's rank-order test. Multiple regression analysis was performed using BMI or MNA-SF as a response variable. All statistical analyses were performed using Excel Statistics (Version 2012). A p-value of $<0.05$ was considered significant.

\section{Results}

\section{Nutritional parameters}

Data on various nutritional parameters are summarized in Table 2. Results from MNA-SF showed that 13 patients $(27.1 \%)$ were at a risk of malnutrition, whereas no patients were malnourished. In contrast, BMI of $<18.5 \mathrm{~kg} / \mathrm{m}^{2}$, an indicator of thinness, was seen only in four patients (8.3\%). Analysis of the blood markers, using the CONUT criteria (11), albumin, total cholesterol levels and total lymphocyte counts, were low in 3 $(6.3 \%), 21(43.8 \%)$, and 12 patients $(25.0 \%)$, respectively.
The results did not significantly differ between sexes; however, when evaluated as a continuous variable, albumin level was significantly lower in males than in females. While differences in terms of sex was marginal $(0.05<p<0.1)$, total cholesterol levels tended to be higher in females than in males. Low pre-albumin levels, as judged by the Japanese criteria, were found in 5 patients $(11.1 \%)$. Correlation efficiency between albumin and prealbumin levels was 0.27 , demonstrating weak statistical significance $(p=0.059)$. Finally, in the comprehensive analysis of laboratory tests consisting of 3 parameters (albumin, total cholesterol levels and total lymphocyte counts), 40 patients (83.3\%) were found to be healthy, whereas only 1 patient $(2.1 \%)$ was found to be moderately undernourished.

\section{Nutritional intakes}

Table 3 depicts the nutritional intakes obtained by FFG3.5. Analysis of caloric intake and ingestion of 3 major nutrients (protein, lipid, and carbohydrate), as adjusted by body weight, showed that females consumed more than males except carbohydrate. In contrast, no difference was found in total daily caloric and protein intakes between males and females. 15 patients $(31.3 \%)$ showed caloric intakes below EER and $6(12.5 \%)$ patients showed protein intakes below estimated average requirement 
Table 3

Comparison of nutritional intakes

\begin{tabular}{|c|c|c|c|c|}
\hline & All & Male & Female & p-value \\
\hline Total (n) & 48 & 13 & 35 & \\
\hline Calorie (kcal/kg/day) & $31.9[13.2-56.9] \S$ & 25.2 [19.7-42.6] & 34.9 [13.2-56.9] & $0.033+$ \\
\hline Protein (g/kg/day) & $1.1[0.4-2.0]$ & $0.9[0.5-1.5]$ & $1.2[0.4-2.0]$ & $0.008+$ \\
\hline Lipid (g/kg/day) & $1.0[0.2-1.8]$ & $0.7[0.5-1.3]$ & $1.1[0.2-1.8]$ & $0.013+$ \\
\hline Carbohydrate (g/kg/day) & $4.2[1.4-7.9]$ & $3.9[2.7-7.0]$ & $4.5[1.4-7.9]$ & $0.141+$ \\
\hline Calorie (kcal / day) & 1766 [824-2487] & 1671 [944-2079] & 1791 [824-2487] & $0.471+$ \\
\hline$<\mathrm{EER}^{*}$ (kcal/day) & $15(31.3) \prod$ & $7(53.8)$ & $8(22.9)$ & $0.046 \neq$ \\
\hline Protein (g/day) & $63.2[23.1-101.6]$ & $56.5[26.4-76.7]$ & 65.1 [23.1-101.6] & $0.079+$ \\
\hline < EAR* (g/day) & $6(12.5)$ & $3(23.1)$ & $3(8.6)$ & $0.323 \ddagger$ \\
\hline
\end{tabular}

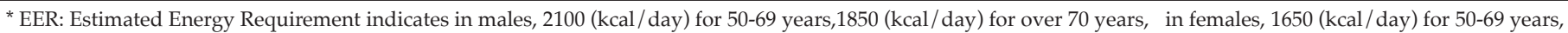

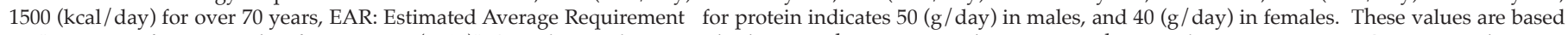

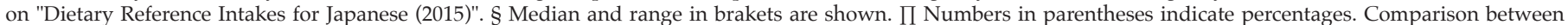
"Male" and "Female" groups done by+Mann-Whitney U test ₹ Chi-squared test or Fisher's exact test

(EAR) established on the Dietary Reference Intakes for Japanese (2015) (17). This reference recommends 2100 $\mathrm{kcal} /$ day for males aged 50-69 years, $1850 \mathrm{kcal} /$ day for males aged $>70$ years, $1650 \mathrm{kcal} /$ day for females aged 50-69 years, and $1500 \mathrm{kcal} /$ day for females aged $>70$ years. EAR for protein recommends $50 \mathrm{~g} /$ day for males and $40 \mathrm{~g} /$ day of protein for females. The rate of males below EER recommendations was significantly higher than that of females.

\section{Multiple regression analysis}

As shown in Table 4, significant, positive associations were found between albumin levels and both BMI and MNA-SF. Furthermore, a negative association was found between females and MNA-SF.

\section{Table 4}

Correlation between BMI or MNA-SF and various parameters by multiple regression analysis

\begin{tabular}{|c|c|c|c|c|}
\hline Response variables* & BMI & & MNA-SF & \\
\hline Explanatory variables & $\begin{array}{c}\text { Correlation } \\
\text { coefficient }\end{array}$ & p-value & $\begin{array}{c}\text { Correlation } \\
\text { coefficient }\end{array}$ & $\mathrm{p}$-value \\
\hline Age (years) & 0,01 & 0,734 & 0,01 & 0,663 \\
\hline Sex (male,0: female,1) & $-0,73$ & 0,202 & $-1,34$ & 0,0067 \\
\hline BMI (kg/m2) & & & 0,22 & $<0.001$ \\
\hline Calorie (kcal / kg / day) & 0,15 & 0,336 & 0,46 & 0,332 \\
\hline Protein (g/kg/day) & 0,68 & 0,582 & $-1,26$ & 0,903 \\
\hline Albumin (g/dl) & 1,26 & 0,043 & 1,67 & 0,012 \\
\hline Total lynphocytes $(\mu 1)$ & 0,001 & 0,731 & 0,001 & 0,921 \\
\hline Total cholesterol (mg/dl) & $-0,004$ & 0,645 & $-0,002$ & 0,981 \\
\hline Pre-albumin (mg/dl) & 0,032 & 0,528 & 0,035 & 0,414 \\
\hline
\end{tabular}

* Coefficient of determination $\left(\mathrm{R}^{2}\right)$ for BMI, 0.38; MNA-SF, 0.49

\section{Discussion}

Nutritional status is a key determinant of health, particularly in the older adult population (2-4). Dwelling type and age have been found to influence malnutrition prevalence of malnutrition. There are nutritional assessments that focus on older adults within certain dwellings, including community dwellings (1822), hospital (23) and nursing home (24). In reviewing available data on malnutrition by MNA, Cereda et al. reported considerable differences in malnutrition prevalence by clinical setting, with $3.1 \%$ prevalence in communities, $8.7 \%$ in homecare services, $22.0 \%$ in hospitals, and $29.4 \%$ in rehabilitation/sub-acute care clinics (25). Considering the growing older adult population, the nutritional assessment of those living in community settings is essential for early detection and early intervention of malnutrition.

This study used MNA-SF as a screening tool for malnutrition and risk of malnutrition. Consequently, 13 patients $(27.1 \%)$ were found to be at a risk of malnutrition, without differences in terms of sex. None of our patients were found to be malnourished. Previous studies performed in Japan revealed that $12.6 \%$ were at a risk of malnutrition based on MNA (18) and 34.7\% (26) on MNA-SF. On the other hand, the reports from Europe $(19,21,22)$ and China (20) using either MNA or MNA-SF demonstrated the rates of the sum of malnutrition at risk and malnutrition were 22.5-76.1\%. Subject numbers of these studies are not large enough to discuss the reason(s) for the different prevalence at present. However, studies targeting at the population with older age, more than 80 years old, tended to demonstrate higher prevalence of malnutrition $(20,21)$.

Albumin, the most abundant protein in the plasma, works as an indicator of nutritional status, although inflammation and liver function have an effect on its metabolism, which often impacts results $(9,10)$. 
When albumin levels of $<3.5 \mathrm{~g} / \mathrm{dl}$ are defined as hypoalbuminemia $(11,27), 3$ patients $(6.3 \%)$ in our study demonstrated hypoalbuminemia, a cutoff value indicating malnutrition.. This prevalence is similar to other studies on the older adult population. One study reported that $3.1 \%$ of patients had hypoalbuminemia among 4,115 patients aged 71 years and elder (27), and a Japanese study reported that among 1130 patients aged $\geq 65$ years, $2.4 \%$ of males and $1.5 \%$ of females had hypoalbuminemia (28). Furthermore, in our multiple regression model, albumin levels were shown to be independently associated with MNA-SF and BMI. This association with MNA-SF is consistent with previous reports by Ülger et al. (19) and Ji et al. (20). Taken together, albumin can work as a good marker for nutritional status assessment in older adults. Pre-albumin is used in evaluating acute nutritional changes because of its shorter half-life than albumin (9). Because the reference value for pre-albumin has not been well established, we used the cutoff value presented by Takeda et al. (15) and demonstrated low levels in 5 patients $(11.1 \%)$. This prevalence of low pre-albumin was almost identical to a report among the French older adults, using the cutoff of $20 \mathrm{mg} / \mathrm{dl}$ (29). This study also demonstrated that prealbumin levels weakly correlated with albumin levels.

Several methods exist for evaluating nutritional intakes, including validated FFQ, dietary history, 24-h recall, and dietary records of $\geq 3$ days (30). Among them, we have chosen the validated FFQ (16) by a face-toface interview because of the possible impairment of cognition in the older adult population. EAR for energy presented by the World Health Organization (WHO) is based on a physical activity score of 1.6 and body weight of $80 \mathrm{~kg}$ for men and $65 \mathrm{~kg}$ for women (30). Because these values are much greater than the Japanese standards, we adapted our own reference values established on the basis of Dietary Reference Intakes for Japanese (2015), to mirror similar Japanese reports $(14,16)$. Our findings indicate that the nutritional intakes in females were more desirable than in males. Namely, caloric and protein intakes in females tended to be higher than those in males. Therefore, older adult males in Japan may have the possibility of becoming malnourished in their later life.

The present study has several limitations. First, the number of subjects was small because only $15 \%$ of the 330 initially enrolled patients agreed to participate. However, as shown in Table 1, the basic characteristics, including sex, age, BMI, and underlying disease status, between initially enrolled population and the study population were statistically similar. Second, other factors related to older adult nutritional status (i.e., presence of depression, level of dependence, and physical activity) were not included. In fact, previous studies have shown that these factors were independently associated with malnutrition of older adults in the community (18-22, 25). Finally, although we checked the presence of underlying diseases, including non-communicable diseases, we were unable to incorporate these data into the analysis. The reason behind this is that the status of controlling the disease is quite diverse among patients, even if the clinical diagnosis is the same. In spite of these limitations, the present study is quite informative because comprehensive parameters, i.e., malnutrition screening tool (MNA$\mathrm{SF}$ ), anthropometry (BMI), laboratory tests (albumin, pre-albumin, cholesterol, total lymphocyte counts, and CONUT scores), and nutritional intakes (FFQ) were measured simultaneously. In conclusion, Japanese older adults in the community are fairly well nourished; however, the nutritional intake study indicates that older adult males may be at higher risk of malnutrition in the future than women. Community caregivers should take note of this finding and update their care plans accordingly.

Acknowledgments: This research did not receive any specific grant from funding agencies in the public, commercial, or not-for-profit sectors. The authors would like to thank Enago (www.enago.jp) for their pertinent advice on the present review.

Conflict of interests: The authors declare that they have no conflicts of interest.

Ethical standard: We have obtained only "verbal consent" from the participants. Instead of the formal written consent, the chief physician (S.Shinozuka) explained the details of the study and, when their consent was obtained, he described it in the patient's chart with his signature. This study was "an observational study" without any invasive procedures. Namely, blood samples were obtained from the participants as one of the regular clinical works, not specifically for this clinical research. In the study of nutritional intake, "no specific" intervention was performed. We just checked the participants' daily diet life using FFQ. Therefore, we thought that the procedure described above (no.1) was enough from the point of ethics and for protection of patients' right. This whole procedure of obtaining the informed consent was approved by the ethical committee at Nara Women's University before starting this research, as described in the text. This study was conducted in accordance with the Declaration of Helsinki

\section{References}

1. Ministry of Internal Affairs and Communications, Japan, A national census (2015), http: / / www.stat.go.jp/data/kokusei / 2015/kekka/kihon1/pdf / youyaku.pdf Accessed 1 April 2016

2. Artacho R, Lujano C, Sanchez-Vico AB, et al. Nutritional status in chronicallyill elderly patients. Is it related to quality of life? J Nutr Health Aging 2014;18:192-197.

3. Grattagliano I, Mastronuzzi T. Nutrition as a health determinant in elderly patients. Curr Med Chem 2017 doi: 10.2174/09299867324666170523125806.

4. Shlisky J, Bloom DE, Beaudreault AR, et al. Nutritional considerations for healthy aging and reduction in age-related chronic disease. Adv Nutr 2017;8:17-26.

5. Guigoz Y. The Mini Nutritional Assessment (MNA) review of the literatureWhat does it tell us? J Nutr Health Aging 2006;10:466-485.

6. Kondrup J, Allison SP, Elia M, Vellas B, Plauth M. Educational and Clinical Practice Committee, European Society of Parenteral and Enteral Nutrition (ESPEN). ESPEN guidelines for nutrition screening 2002. Clin Nutr 2003;22:415-421.

7. Kaiser MJ, Bauer JM, Ramsch C, et al. Validation of the mini nutritional assessment short-form (MNA-SF): a practical tool for identification of nutritional status. J Nutr Health Aging 2009;13:782-788.

8. Silva Rodrigues RA, Martinez Espinosa M, Duarte Melo C, Rodrigues Perracini M, Rezende Fett WC, Fett CA. New values anthropometry for classification of nutritional status in the elderly. J Nutr Health Aging 2014;18:655-661.

9. Omran ML, Morley JE. Assessment of protein energy malnutrition in older persons, part II: Laboratory evaluation. Nutrition 2000;16:131-140.

10. Cabrerizo S, Cuadras D, Gomez-Busto F, Artaza-Artabe I, Ciancas FM, Malafarina V. Serum albumin and health in older people: Review and meta analysis. Maturitas 2015;81:17-27.

11. Ignacio de Ulibarri J, González-Madroño A, de Villar NGP, et al. CONUT: A tool for controlling nutritional status. First validation in a hospital population. Nutr Hosp 2005;20:38-45.

12. Lorenzo-López L, Maseda A, de Labra C, Regueiro-Folgueira L, RodríguezVillamil JL, Millán-Calenti JC. Nutritional determinants of frailty in older adults: A systematic review. BMC Geriatr 2017;17:108 
13. de Vries JHM, de Groot LCPGM, van Staveren WA. Dietary assessment in elderly people: experiences gained from studies in the Netherlands. Eur J Clin Nutr 2009;63(suppl 1) S69-S74.

14. Iizaka S, Kaitani T, Nakagami G, Sugama J, Sanada H. Clinical validity of the estimated energy requirement and the average protein requirement for nutritional status change and wound healing in older patients with pressure ulcers: A multicenter prospective cohort study. Geriatr Gerontol Int 2015;15:1201-1209.

15. Takeda H, Ishihama K, Fukui T, et al. Significance of rapid turnover proteins in protein-losing gastroenteropathy. Hepatogastroenterology 2003;50:19631965.

16. Nozue M, Ishikawa M, Takemi $\mathrm{Y}$, et al. Prevalence of inadequate nutritional intake in Japanese community-dwelling older adults who live alone. J Nutr Sci Vitaminol 2016;62:116-122.

17. Dietary Reference Intakes for Japanese (2015) The Minister of Health Labor and Welfare (Japan) http:/ / www.mhlw.go.jp/ file/06-Seisakujouhou10900000-Kenkoukyoku/Overview. pdf Accessed 1 April 2016

18. Iizaka S, Tadaka E, Sanada H. Comprehensive assessment of nutritional status and associated factors in the healthy, community-dwelling elderly. Geriatr Gerontol Int 2008;8:24-31

19. Ülger Z, Halil M, Kalan I, et al. Comprehensive assessment of malnutrition risk and related factors in a large group of community-dwelling older adults. Clin Nutr 2010;29:507-511.

20. Ji L, Meng H, Dong B. Factors associated with poor nutritional status among the oldest-old. Clin Nutr 2012;31:922-926.

21. van Bokhorst-de van der Schueren MAE, Lonterman-Monasch S, de Vries OJ, Danner SA, Kramer MHH, Muller M. Prevalence and determinants for malnutrition in geriatric outpatients. Clin Nutr 2013;32:1007-1011.

22. Hernández-Galiot A, Goñi I. Quality of life and risk of malnutrition in a home-dwelling population over 75 years old. Nutrition 2017;35:81-86

23. Drescher T, Singler K, Ulrich A, et al. Comparison of two malnutrition screening methods (MNA and NRS 2002) and their association with markers of protein malnutrition in geriatric hospitalized patients. Eur J Clin Nutr 2010;64:887-893.

24. Lilamand M, Kalaiditi E, Demougeot L, Rolland Y, Vellas B, Cesari M. The Mini Nutritional Assessment-Short Form and mortality in nursing home residents-results from the INCUR study. J Nutr Health Aging 2015;19:383388.

25. Cereda E, Pedrolli C, Klersy C, et al. Nutritional status in older persons according to healthcare setting: A systematic review and meta-analysis of prevalence data using MNA. Clin Nutr 2016;35:1282-1290.

26. Htun NC, Ishikawa-Takata K, et al. Screening for malnutrition in community dwelling older Japanese: Preliminary development and evaluation of the Japanese nutritional risk screening tool (NRST). J Nutr Health Aging 2016;20:114-120.

27. Salive ME, Cornoni-Huntley J, Phillips CL, et al. Serum albumin in older persons: Relationship with age and health status. J Clin Epidemiol 1992;45:213-221.

28. Gomi I, Fukushima H, Shiraki M, et al. Relationship between serum albumin level and aging in community-dwelling self-supported elderly population. J Nutr Sci Vitaminol 2007;53:37-42

29. Cals MJ, Bories PN, Devanlay M, et al. Extensive laboratory assessment of nutritional status in fit, health-conscious, elderly people living in the Paris area. Research Group on Aging. J Am Coll Nutr 1994;13:646-657.

30. ter Borg S, Verlaan S, Mijnarends DM, Schols JM, de Groot L, Luiking YC. Macronutrient intake and inadequacies of community-dwelling older adults, a systematic review. Ann Nutr Metab 2015;66:242-255. 